\title{
WILDLIFE AND FENCES
}

by Hugh C. Smith, Provincial Museum and Archives of Alberta, Edmonton

Recently Cornwell and Hochbaum (1971) outlined the effect that fences, and telephone and power lines had on the mortality of waterfowl. However, waterfowl are not the only animals affected. The following examples are of mammals and birds killed by wires.

In 1969, while on a field trip for the Provincial Museum and Archives of Alberta, I came across the carcass of a pronghorn (Antilocapra americana) that was entangled in a fence. The fence, located on the property of the Manyberries Dominion Range Experimental Station approximately 30 miles southeast of Manyberries, Alberta, was of woven wire construction with two or three strands of barbed wire on top. Apparently the pronghorn, a doe, had attempted to jump the fence. One of her hind legs failed to clear the top strand of barbed wire and she was tripped. In thrashing about trying to free herself she entangled her other

${ }^{1}$ Natural History Contribution Number 11 of the Provincial Museum and Archives of Alberta. hind leg. When found, she had been dead for several days. Although pronghorns have the ability to jump, it is a skill that must be learned (Van Wormer, 1969), and they usually cross fences by crawling beneath or through them. Because the fence was flush to the ground there was no way for a pronghorn to crawl under it, and possibly the lack of experience in jumping caused this pronghorn to misjudge the height of the fence.

Another incident of an encounter with a wire fence is illustrated in Fig. 1. The two mule deer (Odocoileus hemionus) were found dead on the farm of Mr. Edward Wesslen of Blackfalds, Alberta, on November 5, 1971. The antlers, which appear to be locked, are held together with strands of barbed wire. It appears that the deer approached each other from opposite sides of the fence and in the ensuing fight became tangled in the fence. In trying to free themselves they tore out 100 feet of fencing and several fence posts. This type of accident is no doubt rare; however, Shaw (1955) reports

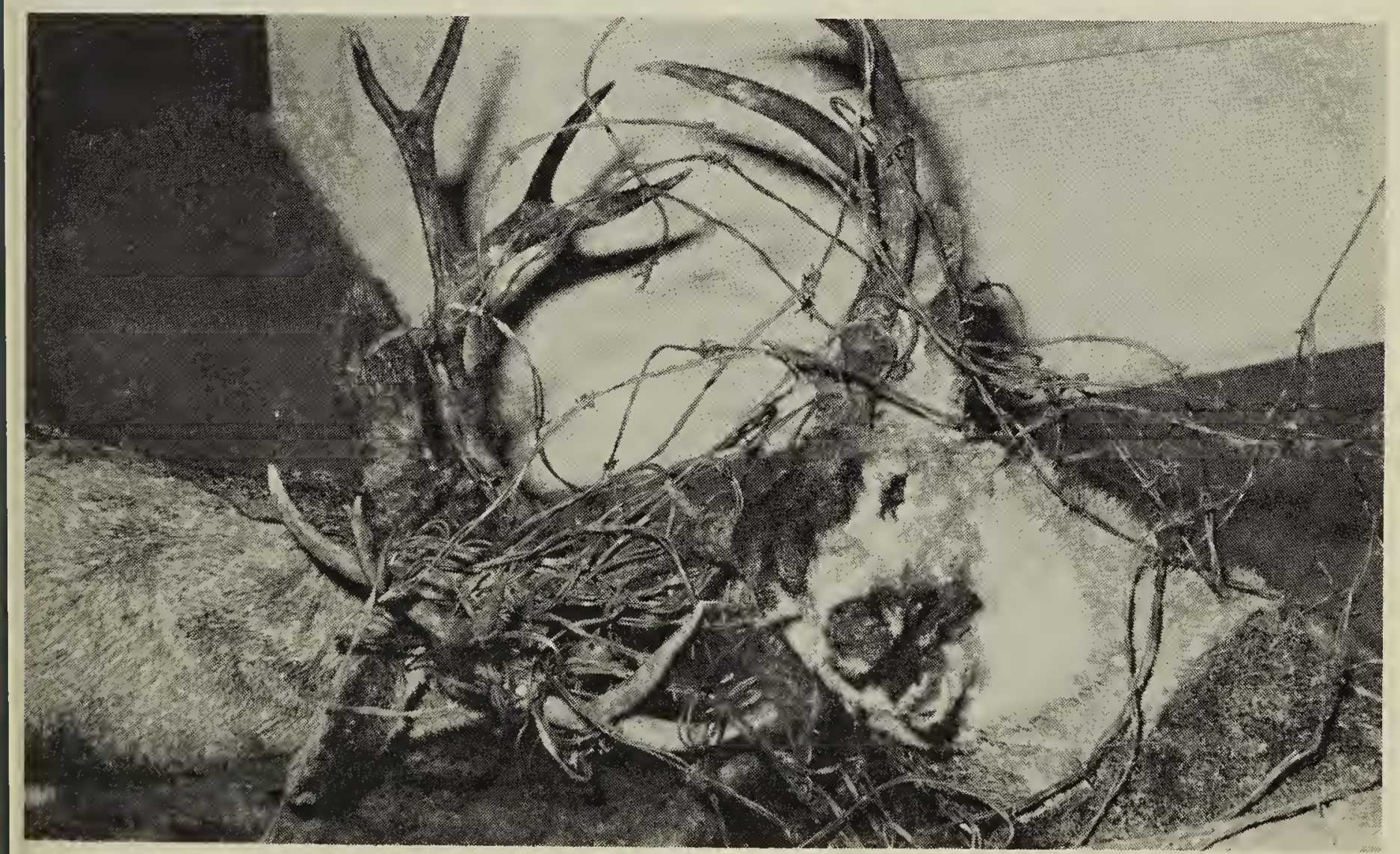

Fig. 1. Mule deer, Blackfalds, Alberta, November, 1971. 


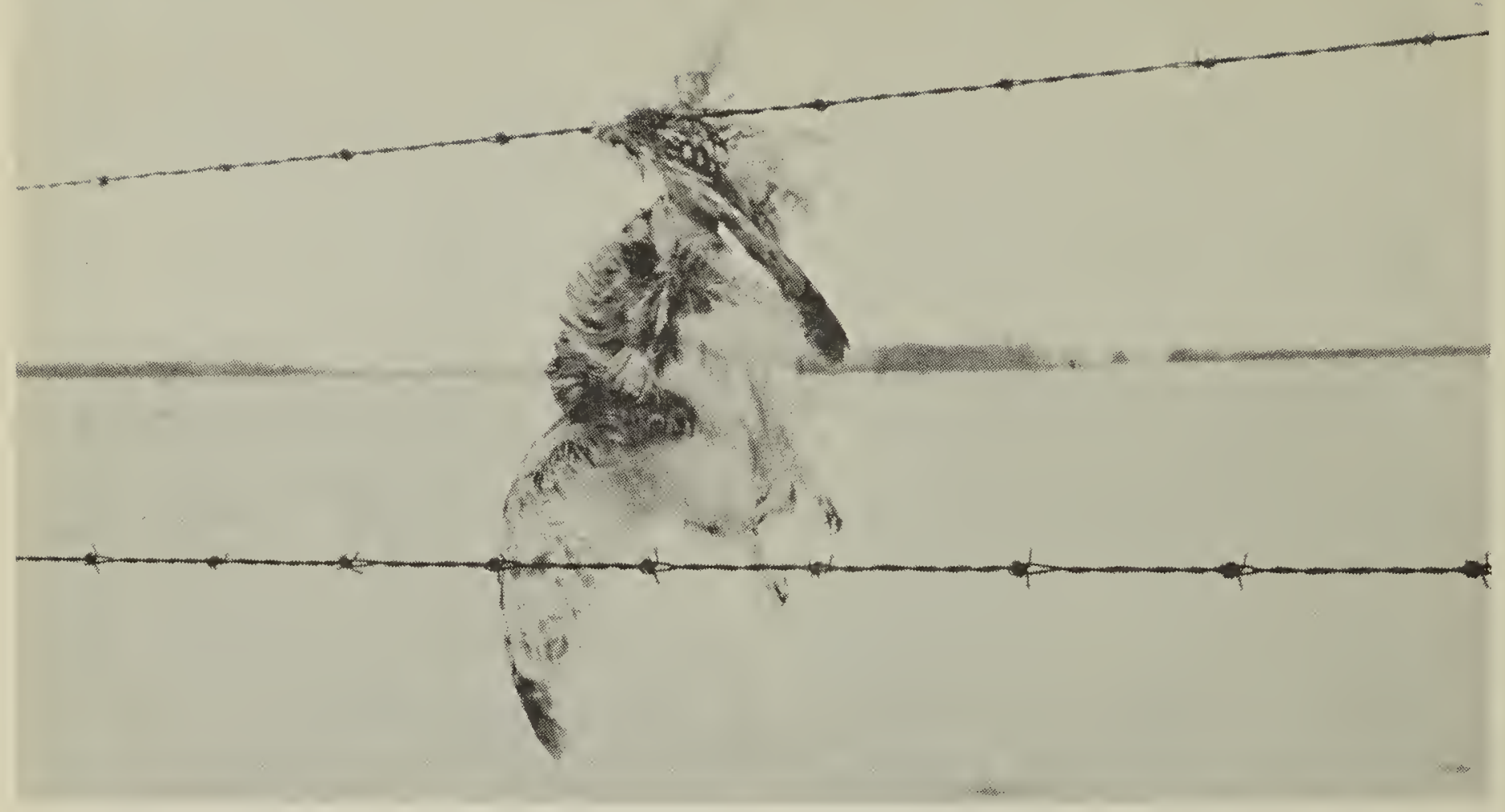

Fig. 2. Short-eared owl, Lacombe, Alberta, February, 1970.

an almost identical situation involving White-tailed Deer (Odocoileus virginianus).

Fig. 2 shows a Short-eared Owl (Asio flammeus) caught on a barbed wire fence. At first it appeared as if someone had shot the bird and had hung it on the fence. It had, however, apparently struck the fence while flying, and one wing had become impaled on a barb. The carcass was dry and brittle when found, and the wing broke off when the bird was removed from the wire.

Another example of a bird striking a wire involved a Willet (Catoptrophorus semipalmatus). During the summer of 1971, while travelling south of Cypress Lake, Saskatchewan, I saw the Willet entangled in a barbed wire fence. On examination I found that it was a young bird which had caught its wing on a barb. The wing was not broken, but there was a long tear in the skin, and a considerable amount of blood had been lost. I was able to remove the bird from the wire, and, as it was still alive, I released it at a nearby slough. Its weakened condition, however, would reduce its chance of survival.
In all these cases barbed wire was involved in some way. Unfortunately, the solution offered by Cornwell and Hochbaum (1971), of removing unused fences and wires from the vicinity of marshes, does not apply here. In most of these situations the fences were boundary fences used to separate fields from the public right-of-way. What the solution is in this context is unclear, for it seems that whenever man wishes to delimit his property he uses a fence of some nature. In Alberta and Saskatchewan barbed wire is the most economical and widely used fencing material. Hence, the elimination of this material for fence construction is not a practical solution to the problem.

It may eventually be a case of wildlife's adjusting to man-made structures. Those that are able to live in the vicinity of such structures and survive are possibly the individuals best suited to carry on the species.

\section{LITERATURE CITED}

Cornwell, G. and H. A. Hochbaum. 1971. Collisions with wires a source of anatid mortality. Wilson Bulletin $83: 305-306$.

Shaw, C. 1955. Battle to death. Blue Jay $13: 21$.

Van Wormer, J. 1969. The world of the pronghorn. J B Lippincott Co., Philadelphia and New York. pp. 1-191. 